\title{
Business process modelling: Review and framework
}

\author{
Ruth Sara Aguilar-Savén* \\ Department of Production Economics, Linköping Institute of Technology, SE 58183 Linköping, Sweden
}

Received 18 April 2002; accepted 9 April 2003

\begin{abstract}
A business process is the combination of a set of activities within an enterprise with a structure describing their logical order and dependence whose objective is to produce a desired result. Business process modelling enables a common understanding and analysis of a business process. A process model can provide a comprehensive understanding of a process. An enterprise can be analysed and integrated through its business processes. Hence the importance of correctly modelling its business processes.

Using the right model involves taking into account the purpose of the analysis and, knowledge of the available process modelling techniques and tools. The number of references on business modelling is huge, thus making it very time consuming to get an overview and understand many of the concepts and vocabulary involved. The primary concern of this paper is to make that job easier, i.e. review business process modelling literature and describe the main process modelling techniques. Also a framework for classifying business process-modelling techniques according to their purpose is proposed and discussed.
\end{abstract}

(C) 2003 Elsevier B.V. All rights reserved.

Keywords: Business process modelling; Enterprise modelling; Modelling tools; Modelling techniques

\section{Introduction}

Value-adding processes have become more and more the principle of organising the business, rather than a functional hierarchy perspective. Some business processes application examples can be found in Swanson (2003), Artiba (2001), Guinet (2001), Martínez et al. (2001), Al-Mubarak (2003) and Chan (2002) to mention a few. Hence the modelling of business processes is becoming increasingly popular. Both experts in the field of Information Technology and Business Engineering have concluded that successful systems start with

*Tel.: + 46-13-285785; fax: +46-13-288975.

E-mail address: ruth.saven@ipe.liu.se (R.S. Aguilar-Savén). an understanding of the business processes of an organisation. Furthermore, business processes are a key factor when integrating an enterprise (Aguilar-Savén and Olhager, 2002). Conceptual modelling of business processes is deployed on a large scale to facilitate the development of software that supports the business processes, and to permit the analysis and re-engineering or improvement of them.

Even though it was 1960 when Levitt first mentioned the importance of business processes it was not until the last decade that processes have acquired a real importance in enterprise design (Levitt, 1960). Authors such as Harrington (1991), Davenport (1993) and Hammer (1990), among others, promoted the new perspective. The 
increasing popularity of business process orientation (Hammer and Champy, 1993) has yielded a rapidly growing number of methodologies, and modelling techniques and tools to support it. The process of selecting the right technique and the right tool has become more and more complex not only because of the huge range of approaches available but also due to the lack of a guide that explains and describes the concepts involved. For example, when searching the Internet for guides on business process modelling many thousands of references may be found. There is therefore a need to aid practitioners and academics alike in filtering the wealth of data available on business process modelling so that they do not spend excessive time and effort in undertaking repetitive searches. Instead, they can dedicate themselves to reviewing, understanding and applying many of the associated concepts and vocabulary.

The aim of this paper is two-fold. On the one hand, it is to review a number of business process modelling techniques and tools. On the other hand, it is to propose a framework to classify the techniques according to their purpose as a guide to practitioners and academics who may need to choose from these techniques.

As the research approach followed, the author conducted a literature search on the state of business process modelling techniques and tools using as research sources scholarly and trade literature both in scientific journals and material on the web. Searching on the Internet yielded a considerable amount of data although as an initial source of information it was difficult to filter. Web sources are useful for further detailed and specific information on certain techniques or tools and especially in identifying tool availability and potential vendors. With the aid of a number of databases, such as Cambridge Scientific AbstractsInternet Database Service, IEEE Xplore and Compendex by Engineering Information Inc., more than 7000 scientific journals and conference proceedings since 1985 were reviewed. The key words used during the search were business process modelling and/or review or framework. Most of the papers found are published in journals or proceedings related to Information Systems or Computer Sciences. The oldest paper is dated 1993 and published by "Information and Software Technology" (Macintosh, 1993).

The focus of the present review therefore is on available techniques and tools explicitly aimed at modelling business processes. These last three words have been the key during the search. Nevertheless, the author is aware that other techniques might exist that are used or that might be used for modelling business processes, which are not referred in the literature. Such techniques have not been identified in this review since all modelling techniques applicable to processes in general are applicable to business processes in particular. However, whether all business process modelling techniques and tools are applicable or not to process modelling is beyond the scope of this paper. The author of this paper confines attention to business processes and the set of modelling techniques applicable to them. In the remainder of this paper the terms "processes" and "modelling techniques" are used in this more limited sense.

This section presents the background of the present research, its aim, and the research approach followed as well as its scope. Section 2 builds the proposal framework used in Section 5 based on the literature survey and highlights some relevant associated concepts. Section 3 describes briefly the main process modelling techniques where some of their key factors are identified. Also some of their strengths and weaknesses are discussed. Section 4 describes some of the generic methodologies with their process modelling capabilities. A classification of the techniques described in Sections 3 and 4 is proposed in Section 5 as a framework to facilitate their selection. Finally, some conclusions and ideas for future research end the paper.

\section{Proposal framework and literature survey}

To study and understand systems, one constructs models according to particular viewpoints and using particular modelling technique. Kettinger et al. (1997a) present an important overview of methods, techniques, and tools used in Business Process Re-engineering (BPR). As part 
of that study a list of some related business process modelling techniques and tools was published. This list does not give detailed descriptions of the techniques nor the tools. However, it has been the starting point of the research presented in this paper, which gives a more thorough overview with detailed analysis of the mentioned techniques in Kettinger et al. (1997b) and others.

It is important to identify the uses or purposes of the models when undertaking modelling of any kind. It seems clear that in order to choose the right technique, the modeller must know the purpose of the model to be constructed. Different techniques are more suitable to certain purposes, e.g. one thing is a model, which describes the process, and another a model to build a system to control the process.

For instance, Phalp et al. (1999) distinguish between two uses of business process models: one for traditional software development, and another to restructure business processes. In Phalp (1998) the latter purpose is explained further arguing that pragmatic approaches are mostly concerned with capturing and understanding processes, while rigorous paradigms are typically used for analysis of the process. Furthermore, it is argued that '...this suggests a need for different notational approaches, for different modelling purposes and audiences' (Phalp, 1998). For software development process typically diagrammatic notation is required, for capturing a legible and understandable view of the business process. Typically the user does not need to play or interact with the model but rather just observe it. When analysing the business process it is necessary to have more sophisticated mechanisms than qualitative analysis of static diagrammatic models, models that present both dynamic and functional aspects of the process. In these cases users might want a model, which permits him/her more interaction (e.g. it might be simulation) to analyse the question "what if'. Finally, in presenting the business process, approaches easy to understand are chosen, again a readily understandable, typically diagrammatic notation is suitable.

Macintosh (1993) defines five levels of process maturity:
1. initial - setting up of processes,

2. repeatable - repeatable processes,

3. defined-documented processes standardised throughout an organisation,

4. managed-measured and controlled processes, and

5. optimising - continuous process improvement.

It is easy to imagine that for each level different models are needed. Levels 1-3 require models whose purposes are to describe the process and thus knowledge of the processes to be captured and analysed. Levels 4 and 5 require models whose purposes are decision support in order to monitor and control processes. Macintosh (1993) proposes to define enriched representations of processes and the use of knowledge-based approaches to design new intelligent tools to model business processes. This permits representations of activities including time, resources, causality and authority although no further details are given. According to Macintosh business process models can be used explicitly to provide decision support in: analysis, process/ plan instantiation and re-engineering.

Giaglis and Doukidis (1997) emphasise business process models use for change management which may be considered in more general terms as the need to learn, analyse, monitor and control the process and thus needing descriptive and decision support models. The most popular of these approaches include: BPR (Hammer, 1990), Continuous Process Improvement (CPI) (Harrington, 1991), Total Quality Management (TQM) (Oakland, 1993), and Organisational Transformation (OT) (Adams, 1984). Other authors such as Workman et al. (2000) claim too that many different models may be needed to analyse business processes depending on the purpose.

Some of these references aim at defining aspects for a business process model to be complete. e.g. Workman et al. (2000) present the historical development of enterprise organisation and information technology distinguishing six phases:

1. the functional hierarchy,

2. the functional hierarchy with function oriented automation,

3. the functional hierarchy with shared database on mainframes, 
4. the process oriented enterprise,

5. the supply chain oriented enterprise, and

6. the web-enabled agile enterprise.

For each historical development phase they explain the main descriptive aspects arguing that for each phase different models have been needed. For phase 4 they emphasise the need of modelling business processes and they define what they called business model architecture. Giaglis and Doukidis (1997) examine the nature of business processes in the light of modern change management approaches and propose a set of requirements for their modelling as follows:

- Technical requirements: formal modelling, quantitative modelling, stochastic modelling, model documentation, model adaptability/reusability and objective-driven modelling.

- Political/social requirements: Feasibility of alternative designs, communication of models and user friendliness.

These requirements are based on the thought that businesses are essentially "socio-technical" systems. Giaglis and Doukidis (1997) show too that simulation can be an invaluable tool for Business Process Modelling (BPM) especially when modelling inter-organisational business processes. They add three additional requirements for inter-organisational business modelling: modular model design, modular model analysis and model decomposition and integration. The idea is to show features that a business process model should have in order to be classified as performing successfully. All requirements identified by Giaglis et al. are basically meant as guidelines for prospective users or developers of business process simulation models. Hence, we can state that to define model requirements that enable it to be considered complete is function of the purpose of the model. In this sense, Phalp (1998) proposes that models used to analyse business processes for developing software should include expert judgements and heuristics, measurements, formality and be executable. In the same context Toussaint et al. (1997) find three essential aspects of processes that models should present, namely: functional, static and dynamic. Jarzabek et al.
(1995) identify information requirements for business re-engineering to build tools that can support business knowledge acquisition, business process modelling, performance/quality analysis and analysis of alternative BPR solutions. Rajala et al. (1996) introduce a new requirement, the customer orientation, and propose a new modelling framework, which integrates customer orientation to business process simulation modelling.

Hommes et al. (2000) give a more general framework to define a business process technique. They identify on the one hand four elements that constitute any individual model: notation, meaning, concept relationship and modelling concept, which are called the way of modelling (modelling concepts). On the other hand there are three elements that constitute the way of working: procedure relationship, activity relationship and activity, which describe the procedures by which the models are constructed (modelling procedure). Hommes et al. framework is focused on describing the modelling technique. Whether the resultant model is adequate or not is another question. Phalp (1998) uses a similar idea, which underlines that notation and method are two important considerations when modelling business processes. Both method and notation will depend on the desired model characteristics, which in turn will depend on the purpose.

Hence, business processes can be described at different levels of detail depending on the abstraction put into analysing the organisation, which depends in turn on the purpose of the analysis. As a result of the literature review, it was identified that business process models are mainly used either to learn about the process, to make decisions on the process or to develop business process software. Usually, these purposes relate to some extent to some model characteristics. That is to say, some business process models are better suited depending on the specific purpose. We suggest a very basic classification of business process models giving attention to their level to allow and facilitate model changes in passive and active. Passive means not to allow changes whereas active means to allow changes. We combine these two dimensions to classify business process models. 


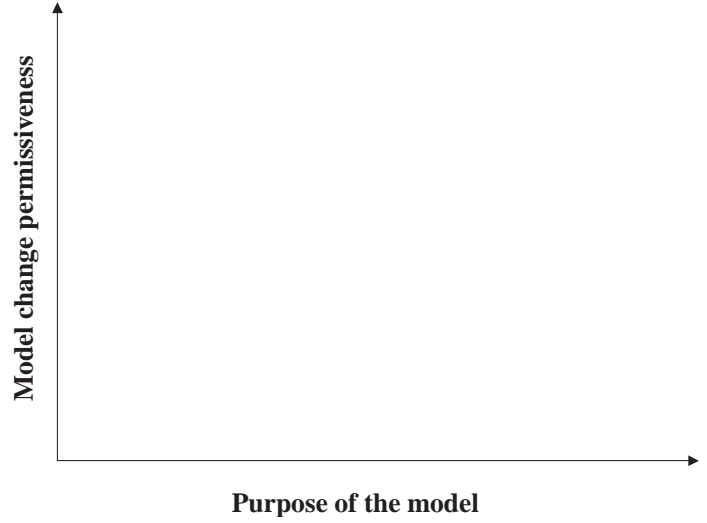

Fig. 1. Classification framework for business process modelling techniques.

This is represented in a matrix with two axes one for each dimension (see Fig. 1).

Concerning the assessment of the quality of $a$ business process modelling technique Hommes et al. (2000) present a set of quality properties and procedures to make an objective assessment of these properties possible called Quality-based Modelling Evaluation (Q-ME) framework. They link the properties of the model to the way of modelling and working mentioned above. Based on the FRISCO report (Falkenberg et al., 1996) there are three quality properties: expressiveness, arbitrariness and suitability. Other authors such as Barros and Hofstede (1998) and Harmsen (1997) propose other properties such as: comprehensibility, coherence, completeness, efficiency and effectiveness.

In Pandya (1995) a comparison of some methodologies and some modelling tools for business processes is undertaken and a guide showing their suitability in manufacturing management and business processes is proposed. Nevertheless, there is neither a classification of the methodologies and/or tools nor clear distinction between them.

\section{Brief description of the main process modelling techniques}

Before describing any technique we define what a business process is. According to Davenport (1993) processes are defined as "structured, mea- sured sets of activities designed to produce a specified output for a particular customer or market". There are so many other definitions but in essence all are the same: processes are relationships between inputs and outputs, where inputs are transformed into outputs using a series of activities, which add value to the inputs.

It is beyond the scope of this paper to go into further discussion on the difference between business processes and processes in general. It seems that some authors take them as synonymous. For example, in contrast to Davenport, Hammer (1990) defines businesses process as "a collection of activities that takes one or more kinds of input and creates an output that is of value to the customer". However, an important distinction for the author of this paper is that a business process is related to enterprises, as they define the way in which the goals of the enterprise are achieved and thus they are a subset of the set of processes. According to ENV 12204 (1995) a business process is a partially ordered set of Enterprise Activities which can be executed to realise a given objective of an enterprise or a part of an enterprise to achieve some desired end-result.

There are many classifications of business processes too. Often 'core' and 'supportive' business processes are distinguished. A core (or primary) process is initiated from outside an organisation, e.g. the chain of activities that realises the delivery of a product to a customer. A supportive (or secondary) process creates the conditions for the primary process to be carried out. This last might be classified in its turn as management processes that control the organisation's overall strategies and objectives; and support processes, which support the core processes by offering sufficient resources.

There are many business process modelling techniques, as were mentioned above (PROCESS, 2003). As a result of the literature review the following were found as the most frequently used and therefore they are considered as the main techniques. Sections 3 and 4 are a summary of a longer working paper. For further information, details and references of those sections see AguilarSavén (2001). The most important characteristics of each technique are discussed below. 


\subsection{Flow chart technique}

A Flow Chart is defined as a formalised graphic representation of a program logic sequence, work or manufacturing process, organisation chart, or similar formalised structure (Lakin et al., 1996). It is a graphical representation in which symbols are used to represent such things as operations, data, flow direction, and equipment, for the definition, analysis, or solution of a problem. The Flow Chart modelling method uses flowcharts to represent processes. It uses a sequential flow of actions and does not support a breakdown of the activities. The Flow Chart model is possibly the first process notation. It has frequently been used over many years although there is no exact date for its origin.

Fig. 2 depicts an example of a simple process by using a flow chart. The process starts when a customer makes an order to a company. The company's Marketing Department receives the order, introduces the information in the information system at the company and sends the order forward to the Distribution Centre. Distribution Centre verifies the availability of the required products and if they are available they ship the products to the customer together with the invoice, otherwise they inform Marketing of the nonavailability so that Marketing may inform the customer.

The main characteristic of Flow Charts is their flexibility. A process can be described in a wide variety of ways. The standard just gives the notation, but how the different building blocks are put together is up to the designer of the chart. When we look at a flowchart representation, it is easy to recognise the processes it describes. The real strength of the standard is the communication

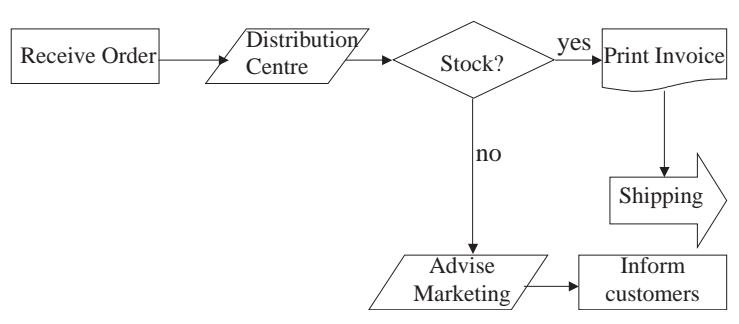

Fig. 2. Example of flow chart. ability. The Flow Chart model is very easy to use. It does not take a very long time to draw a sketch of a process.

The weakness of the standard is that it is too flexible. The boundary of the process may not be clear. Flow charts tend to be very big. Already in the evaluation model, the flowchart can be too large. There is also no difference between main and sub-activities, which makes the chart hard to read. Since there are no sub-layers, it is hard to navigate and it is difficult to find information in the chart. Of course it is easier to follow the course of events, but the risk of getting lost is high. Visualising the process with a flowchart can quickly help identify bottlenecks or inefficiencies where the process can be streamlined or improved.

The best use of Flow Chart technique is when it is used to deal with processes that need a high level of detail. On the contrary, it is not very good for giving an overview. Usually, there is no natural way of describing responsibilities or performers in the chart. This makes it hard to connect the organisational functions, often referred to as 'departments', to activities.

\subsection{Data flow diagrams-Yourdon's technique}

Data flow diagrams (DFD) are diagrams that show the flow of data or information from one place to another. DFDs describe the processes showing how these processes link together through data stores and how the processes relate to the users and the outside world. They are used to record the processes analyses as a part of the design documentation (http://panoramix.univ-paris $1 . \mathrm{fr} / \mathrm{CRINFO} / \mathrm{dmrg} / \mathrm{MME} / \mathrm{misop} 025 / \mathrm{info} . \mathrm{html}$ ) and (http://threesl.com/data_flow_diagrams.htm). A DFD can be seen as a method of organising data from its raw state. DFDs are the backbone of structured analysis that was developed in the early sixties by Yourdon. Fig. 3 depicts the same process as in Fig. 2 although using DFD notation.

By using DFD, the analyst will be able to specify a process at the logical level. This means that he will be able to describe what a process will do, rather than how it will be done. They are used in discussions between analysts and users as they can be easily understood and verified, and are easy to 


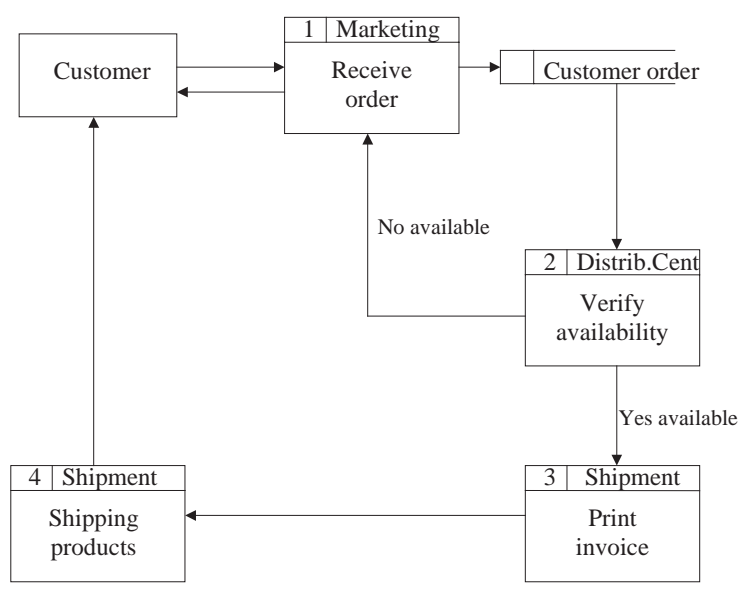

Fig. 3. Example of a data flow diagram.

draw and amend. Each process can be broken down into sub-processes at a lower level to show more detail. They only show the flow of data, not materials. DFD are used in the functional model to specify the meaning of operations and constraints and show functional dependencies. It shows how information enters and leaves the process; what activities change the information; where information is stored within the process, and the organisational function to which the activity belongs.

'Action Diagrams' are a special case of DFD with simpler notation (Goldkuhl and Röstlinger, 1988) and permit a contextual analysis. In this sense, 'action diagrams' represent an exception of DFD because they introduce data concerning the performer, may show both information and material flows, and distinguish between knowledge and information. Fig. 4 shows the action diagram of the same process of Fig. 2.

\subsection{Role activity diagrams $-R A D$}

Role activity diagrams (RADs) are based around a graphic view of the process from the perspective of individual roles, concentrating on the responsibility of roles and the interactions between them (Holt et al., 1983). Roles are abstract notations of behaviour describing a desired behaviour within the organisation. They

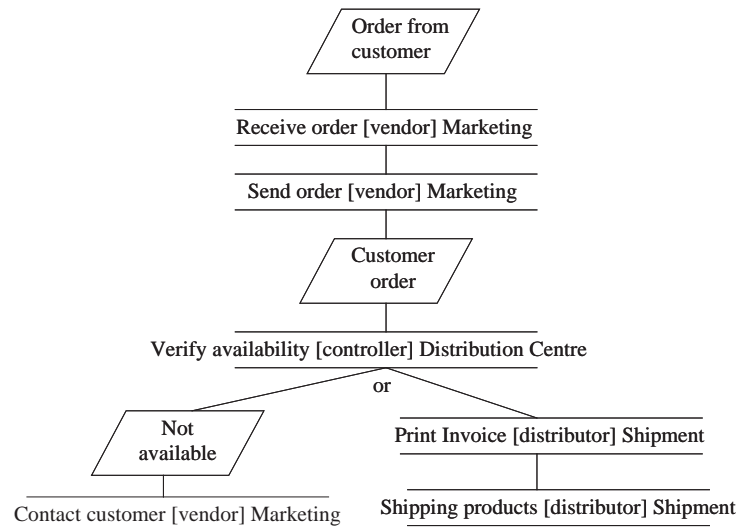

Fig. 4. Example of an 'action diagram'.

are often organisational functions. They also include software systems, customers and suppliers.

RADs provide a different perspective of the process and are particularly useful in supporting communication. They are easy and intuitive to read and understand presenting a detailed view of the process and permitting activities in parallel. With careful modelling, RADs might define the degrees of empowerment within the business and can also demonstrate how processes interact. It can even be used to describe how software systems interact. RADs are, in fact, object state transition diagrams used in object-oriented models. They describe how a role object changes state as a result of the actions and interactions, which occur.

Disadvantages are that the technique explicitly excludes business objects, which are manipulated by the process, as machines or products. The process is presented as a sequence of activities not letting a decomposition of the process, and thus it makes an overview difficult.

\subsection{Role interaction diagrams - RID}

Role interaction diagrams (RIDs) are a graph of a process resulting from the combination of RADs and Jacobson's object interaction diagrams (Boma, 1996). Activities are connected to roles in a type of matrix. Activities are shown vertically on the left axis and the roles are shown horizontally at the top. Text and symbols are used together in order to represent the process. Horizontal lines 


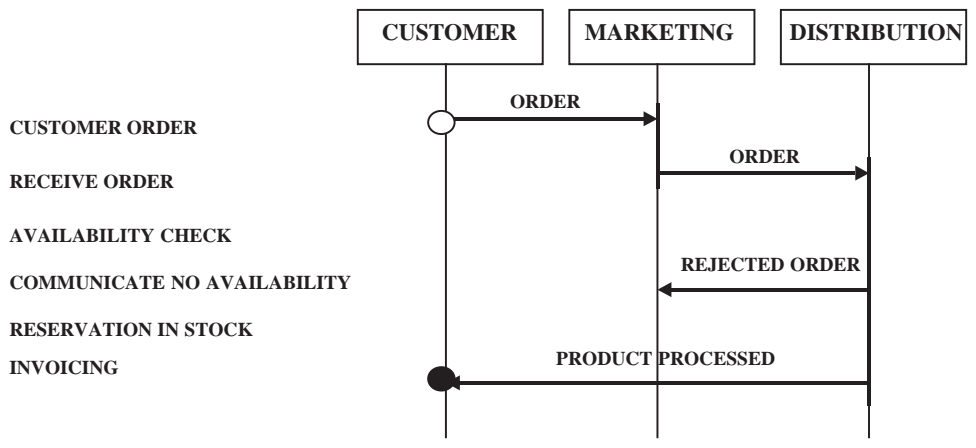

Fig. 5. Example of a RID.

show human interactions (Boma, 1996). Fig. 5 shows the same process as in Fig. 2 using RID.

Although slightly more complex than flow diagrams, RIDs are fairly intuitive to understand, easy to read but they tend to be messy, with many arrows pointing left and right and are therefore quite hard to build. Inputs to, and outputs from the activities are not modelled. Therefore, important information is lost. When editing an existing diagram, it can be hard to insert new activities or roles. When a new activity or a new role is to be inserted, big parts of the diagram have to be moved to allow space. Since each activity is bound to a performer, the responsibilities are well defined and thus the connection to the organisation is easy to make.

RIDs are not as flexible as flowcharts, for example. They have quite rigid notation. But compared with other modelling techniques, RIDs are nevertheless flexible. Due to their notation and ability to break down activities, very complex processes can be displayed. The best use of RIDs is in workflow design. RIDs are primarily used for processes that involve co-ordination of interrelated activities.

\subsection{Gantt Chart}

A Gantt Chart (Aguilar-Savén, 2001) is a matrix that lists on the vertical axis all the tasks or activities to be performed in a process. Each row contains a single activity identification, which usually consists of a number and a name. The horizontal axis is headed by columns indicating estimated activity duration, skill level needed to perform the activity, and the name of the person assigned to the activity, followed by one column for each period in the project's duration. Each period may be expressed in hours, days, weeks, months, and other time units. In some cases it may be necessary to label the period columns as period 1 , period 2, and so on. Gantt charts relate a list of activities to a time scale, thus they might be used to represent a process graphically and control its current situation of performance, although its use to analyse a process is limited. They are very simple graphic representations but they do not show clear dependencies between activities.

\section{6. $I D E F$}

The Integrated Definition for Function Modelling (IDEF) is a family of methods that supports a paradigm capable of addressing the modelling needs of an enterprise and its business areas (IDEF, 2003). IDEF's roots began when the US Air Force, in response to the identification of the need to improve manufacturing operations, established the Integrated Computer-Aided Manufacturing (ICAM) program in the mid-1970s. The requirement to model activities, data, and dynamic (behavioural) elements of the manufacturing operations resulted in the initial selection of the Structured Analysis and Design Technique (SADT). SADT is more than a technique. It is a whole methodology to be used as a regimented approach to analysing an enterprise.

The IDEF family is used according to different applications. The most important parts are: IDEF0, IDEF1, IDEF1X, IDEF2, IDEF3, IDEF4 
and IDEF5. However, for business process modelling, the most useful versions are IDEF0 and IDEF3 and therefore they are explained further below.

IDEF0 is a modelling technique used for developing structural graphical representations of processes or complex systems as enterprises. It is used to specify function models, which are "what do I do?" models. These show the high-level activities of a process indicating major activities and the input, control, output, and mechanisms associated with each major activity. The processes can be further decomposed to show lower-level activities, but at some point the required view may require another notation to portray such things as branch control. These models are composed of three types of information: graphical diagrams, text and glossary. These three types are crossreferenced to each other. The major component is the graphical diagram, containing boxes, arrows, box-arrow interconnections and associated relationships. The IDEF0 format is shown in Fig. 6 to describe the same process as in Fig. 2.

The IDEF0 standard is the most popular process-modelling on the market. The very strict rules in IDEF0 make it suitable for implementation as computer software. By working backwards along the chain from output to inputs, much data and control can be defined. Thus it can be analysed and improved. The hierarchical structure facilitates quick mapping at a high level. One weakness is the tendency of IDEF0 models to be interpreted as representing a sequence of activities. The activities may be placed in a left to right sequence within decomposition and connected with the flows. It is natural to order the activities left to right because, if one activity's output is used as input by another activity, drawing the activity boxes and concept connections is clearer. Thus, without intent, activity sequencing can be embedded in the IDEF0 model.

IDEF1 is used for information modelling, which captures conceptual views of the enterprise's information. IDEF1X is used for data modelling, which captures the logical view of the enterprise's data and is based on an entity relationship model. It is a design method for logical database. IDEF2 Simulation Model Design method is used to represent time varying behaviour of resources in a manufacturing system. Various commercial products and notations have replaced it.

IDEF3 Process Description Capture method is used to capture behavioural aspects of a process. It allows different views of how things work within an organisation. Unlike IDEF0, IDEF3 has been developed for explicitly describing processes. The former shows what is done within the organisation while the latter shows how things work with it. From domain experts, descriptions are captured in which the precedence and causality relationships between activities and events of the process are shown. IDEF3 consists of two modelling modes: the process flow description (PFD), which describes how things actually work in the organisation,

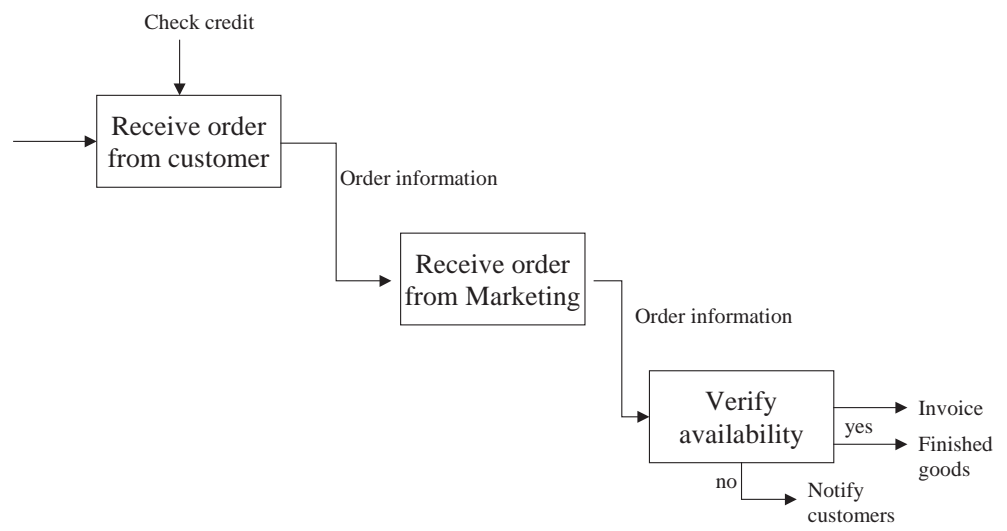

Fig. 6. IDEF0 graphical diagram's components. 
and the object state transition description (OSTD), which summarises an object's allowable transitions in a particular process. It is suitable to model both simple and complex processes due to its decomposition ability.

The basic notation of the IDEF3 method consists of a series of square and oblong boxes, and circles and arcs which link them. Attached to each icon is an elaboration form, which contains a description of that icon, reference label, etc., and a detail of related objects, facts and constrains acting upon it. IDEF3 is used in several areas such as Business Process Engineering (BPE) and Reengineering (BPR), software process definition and improvement, and even in the software development and maintenance.

IDEF4 object-oriented design method was developed to support the object-oriented paradigm. It currently supports design to implement $\mathrm{C}$ language applications. IDEF5 method provides a theoretically and empirically well-grounded method specifically designed to assist in creating, modifying and maintaining ontology. Ontology is a part of philosophy whose goal is to divide the "world" into different objects.

\subsection{Coloured Petri-net-CPN}

Coloured Petri nets is a graphical oriented language for design, specification, simulation and verification of systems. It is particularly well suited for systems that consist of a number of processes, which communicate and synchronise (http://www. daimi.au.uk/PetriNets/tools/quick.html). Coloured nets are extended Petri nets in which symbols are differentiated by "COLOURS". A CPN model consists of a set of modules which each contain a network of places, transitions and arcs. The graphical representation makes it easy to see the basic structure of a complex CPN model, i.e. to understand how the individual processes interact with each other. CP-nets have a formal, mathematical representation with a well-defined syntax and semantics. This representation is the foundation for the definition of the different behavioural properties and the analysis methods. The behaviour of a CPN model can be analysed, either by means of simulation (which is equivalent to program execution) or by means of more formal analysis methods (which are equivalent to program verification).

Petri nets were originally developed in the $1960 \mathrm{~s}$ and 1970s, and they were soon recognised as being one of the most adequate and sound languages for description and analysis of synchronisation, communication and resource sharing between concurrent processes. However, attempts to use Petri nets in practice revealed two serious drawbacks. First of all, there were no data concepts and hence the models often became excessively large, because all data manipulation had to be represented directly in the net structure. Secondly, there were no hierarchy concepts, and thus it was not possible to build a large model via a set of separate submodels with well-defined interfaces. CP-nets incorporate both data structuring and hierarchical decomposition without compromising the qualities of the original Petri nets and thus removed these two serious problems.

Fig. 7 shows a description of an object's behaviour states as an example of a CPN. The object considered in the figure is 'an acknowledgement', which is affected by different activities performed in a process: to send, to receive or to update. According to these activities and a series of rules the object will change: waiting, passive, inactive, etc.

\subsection{Object oriented methods}

The term object orientation (OO) has different meanings. The history of object oriented programming starts with the development of the discrete event simulation language Simula by Dahl and Nygaard in Norway in 1967. Generally, it is used to describe a system that deals primarily with different types of objects, and where the actions one can take depend on what type of object one is manipulating. Thus, OO methods might be defined as methods to model and programme a process described as objects, which are transformed by the activities along the process. The fundamental construct is the "object", which combines both data structure (attributes) and behaviour (operations) in a single entity. Objects may represent real world applications (Rumbaugh et al., 1991). 


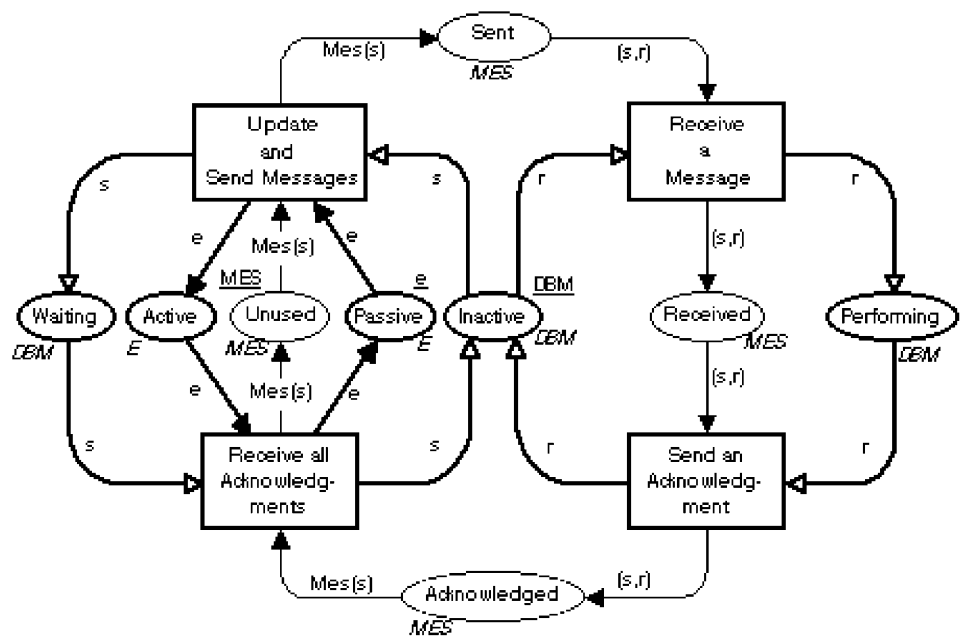

Fig. 7. Example of a CPN.

Benefits of using $\mathrm{OO}$ methods are described in (Bruce, 1998).

This method is based on three concepts: objects that represent a real-world entity. An object has a state, i.e. one of the possible conditions in which the object may exist represented by the values of the properties (attributes). State changes are reflected by the behaviour, i.e. how an object acts and reacts determined by the set of operations the object can perform on itself, and also knowing its interface, functions and methods. A set of similar objects is called class. For example, the attributes for the class animal are having four legs and a tail. Its behaviours is sleeping and eating. Then possible instances or objects of the class animal are cat, elephant, and horse. Finally, messages are requests for the receiver objects to carry out the indicated method or behaviour and return the result of that action to the sender objects. States change through behaviour when the object receives a message.

Coad and Yourdon (1991) mention seven key motivations and benefits in favour of OO methods instead of using other analysis methods. These are

(1) tackle more challenging problem domains,

(2) improve analyst and problem domain expert interaction,
(3) increase the internal consistency across analysis, design and programming,

(4) explicitly represent commonality between classes and objects,

(5) build specifications resilient to change,

(6) reuse OO Analysis and OO Design results, and

(7) provide a consistent underlying representation for analysis, design and programming.

One of the main advantages of OO method is the effectiveness of the process to identify and refine objects.

$\mathrm{OO}$ is one of the main methods used for process modelling, especially when the model needs to be enactable. There are many different techniques based on OO. The main techniques used are:

- Booch's Object Oriented Design (OOD) Technique (Booch et al., 1999) and http://www.slac.standford.edu/ marino/html/booch/method.html,

- Coad and Yourdon's OOA/OOD technique (Coad and Yourdon, 1991; Coad et al., 1995),

- Rumbaught object modelling technique (OMT) (Rumbaugh et al., 1991),

- Shlaer-Mellor Technique, also known as the object-oriented systems analysis (OOSA) (http: //cheetah.sdd.sri.com/eliot/ads/shlaer-mellor. html). 
Differences among those techniques are basically related to their notation. Therefore, we will explain only one called Unified Modelling Language (UML), which is considered the standard OO modelling language. Coad and Yourdon's method precedes UML. For further details on these techniques and OO methodology see Aguilar-Savén (2001).

Unified Modelling Language: UML is a language for specifying, visualizing, constructing and documenting the artefacts of software systems, as well as for business modelling and other non-software systems. UML uses OO methods for modelling. The UML represents a collection of engineering practices that have proven successful in the modelling of large and complex systems, see UML (2003) and Booch et al. (1999) for further information.

The UML covers conceptual things, such as business processes and system functions, as well as concrete things, such as programming-language classes, database schemas, and reusable software components. The Unified Modelling Language serves as a basis for representing most methods using a common set of modelling constructs and a common notation. It captures the concepts from the OMT, Booch, and OOSE methods, but they hope that other methodologists will adopt it also, so that users can understand models from any method without confusion. The UML can be considered as the standard of the entire object oriented community. ${ }^{1}$

The UML consists of nine different diagrams, and each diagram shows a specific static or dynamic aspect of a system: Class diagram, describes the structure of a system. The structures are built from classes and relationships. Object diagram, expresses possible object combinations of a specific class diagram. Statechart diagram, express possible states of a class (or a system). Activity diagram, describes activities and actions taking place in a system. Sequence diagram, shows one or several sequences of messages sent among a set of objects. Collaboration diagram, describes a complete collaboration among a set of objects.

\footnotetext{
${ }^{1}$ A comparison of Object Notations available at: http:// www.cs.queensu.ca/home/stlab/local/UML-paper.html.
}

Use-case diagram, illustrates the relationships between use-cases. Each use-case, typically defined in plain text, describes a part of the total system functionality. Component diagram, a special case of class diagram used to describe components within a software system. Deployment diagram, a special case of class diagram used to describe hardware within a software system.

\subsection{Workflow technique}

In general terms, it is defined as the computerised facilitation or automation of a business process, in whole or in part, during which documents, information or tasks are passed from one participant to another for action, according to a set of procedural rules (Fischer, 1995). Workflow is a flow of tasks between computer applications or people in an organisation. Two or more members of a workgroup to reach a common goal can define workflow as well as any task performed in series or in parallel. Workflow is more than a technique to model a process. It is a method to analyse and improve a process, including its modelling. A work management system is a system that defines, creates and manages the execution of workflow through the use of software whose order of execution is driven by a computer representation of the work logic (Hollingsworth, 1995).

The workflow development process uses workflow models to capture the relevant information of the processes. This process comprises four stages: Information Gathering, Business Process Modelling, Workflow Modelling, and Implementation, Verification and Execution. Fig. 8 shows the basic concepts and terms used in workflow and their relationships. Some advantages are: work not forgotten, shorter learning time, data transfer, process improvement, easier to make changes, decentralisation, workflow can be used in combination with other systems. Disadvantages: lost human contact, lack of motivation, feeling controlled.

There is no particular notation for workflow systems. This is due to the existence of a number of workflow languages, which aim to describe and to specify workflow. Each one of these languages uses a specific notation, sometimes a graphical one, to 


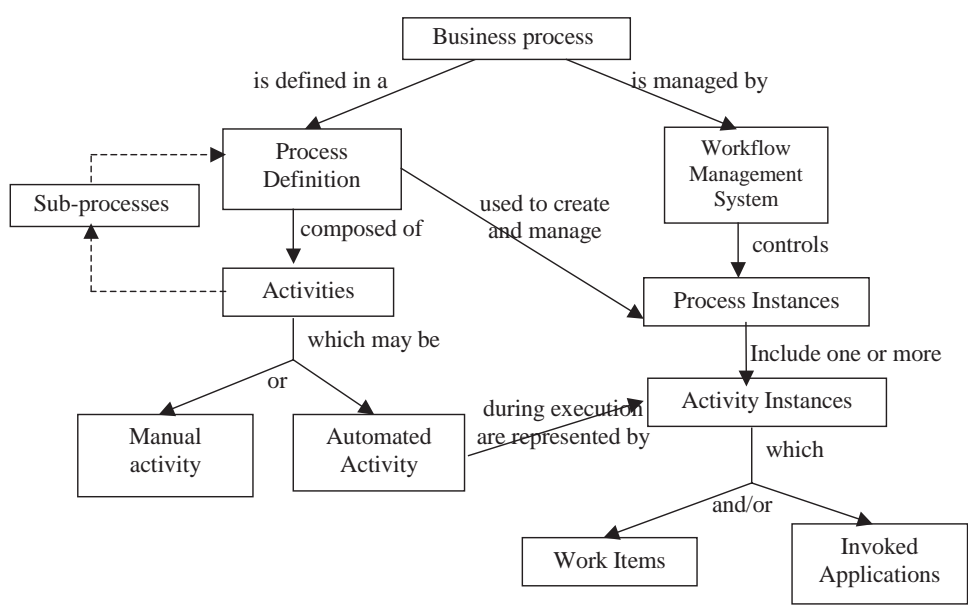

Fig. 8. Concepts of workflow.

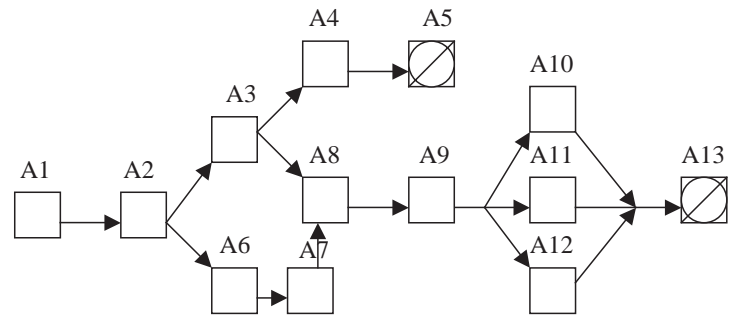

Fig. 9. Example of workflow.

describe the processes. Fig. 9, for example, shows a workflow process description using a graphical notation where arrows represent information flow, and squares are workflow activities. These languages can be classified as: Graph-Based languages, Net-Based languages (based on Petri nets) and Workflow Programming languages.

\section{Generic methodologies}

Sometimes when searching business process modelling techniques names come up that represent more than a technique. They are generic methodologies with process modelling capabilities. Unfortunately those names are often used to point out either the methodology or the modelling technique involved, which may create confusion among practitioners especially to those who are not familiar with these concepts. For example, Open System Architecture for CIM (CIMOSA) and Integrated Enterprise Modelling (IEM) are two methodologies dealing with enterprise integration. As a part of this task they model enterprise business processes. CIMOSA does this by using its own constructs, which are designed to be easily programmed based on OO methods. IEM model business processes by using diagrams based on IDEF0 and by using EXPRESS language that, again, is based on OO methods. In other words, the techniques used within these methodologies to model business processes are based on what has already been explained although calling them CIMOSA and IEM. This means that e.g. CIMOSA and IEM are not different or new business process modelling techniques than those included in Section 3. The aim of this section is to clarify and present some of these cases.

\subsection{SSADM methodology}

Structured systems analysis and design methodology (SSADM) is a methodology used in the analysis and design stages of systems development. It is not considered as a particular technique for process modelling. It is considered as a set of procedural, technical and documentation standards for systems development. SSADM adopts a prescriptive approach to information systems 
development which specifies advance modules, stages and tasks that have to be carried out, the deliverables to be produced and furthermore the techniques used to produce the deliverables. SSADM adopts the Waterfall model of systems development, where each phase has to be completed and signed off before subsequent phases can begin according to Downs et al. (1992) and Nicholas (2003).

SSADM revolves around the use of three techniques, namely Logical Data Modelling, Data Flow Modelling and Entity/Event Modelling. The structure of SSADM consists of five main modules, which are in turn broken down into a complex hierarchy of stages, steps, and tasks: (1) Feasibility Study; (2) Requirements Analysis; (3) Requirements Specification; (4) Logical System Specification; and (5) Physical Design. For the analysis of processes SSADM uses Data Flow Diagrams already explained in Section 3.

\subsection{Soft systems methodology}

Soft Systems Methodology (SSM) is a methodology used to support and to structure thinking about, and intervention in, complex organisational problems. Existing systems, or those yet to be designed, are viewed as social systems, which are derived from human activities. Human activity, behaviour and interaction are all factors that need to be reconstructed, see Soft Systems Methodology web page: http://members.tripod.com/SSM_ Delphi/ssm4.html.

The SSM process consists of seven stages. In these stages, one uses relevant techniques and switches between the real world and the conceptual modelling world where appropriate. These seven stages are: (1) Define the problem situation: unstructured; (2) Express the problem situation; (3) Formulate root definitions; (4) Build conceptual models; (5) Comparison of stages 2 and 4; (6) Define feasible and desirable changes; (7) Take action to improve the situation. This methodology helps to understand and analyse a process from the human perspective. One of the techniques used to describe a process is called Rich Pictures, which are highly contextual representations of things. They represent some of the richness of the situation being examined and illustrate issues that will be considered for analysis, reflection and change. They include components such as clients, people involved, tasks performed and environment. This technique is very useful in understanding the interaction of different elements involved in the process and the interaction between processes, although it is not suitable for a structured analysis, or to report a description.

\subsection{GRAI methodology}

Graph with results and activities interrelated (GRAI) or sometimes called GRAI integrated methodology (GIM) is a methodology developed to address production management decisions in manufacturing systems. As with SSADM, some authors call GRAI a methodology and others call it a technique for process modelling. Actually, strictly speaking GRAI is more than a technique and also GIM, which is a whole methodology (Doumeingts et al., 1996). From the beginning, GIM meant GRAI-IDEF0-Merise. Merise is a method developed in France for the analysis and design of information systems. It is used for designing data models (static models) with Entity/relationships as formalisms, and enactable models (for instance simulation models) based on Petri nets as formalisms.

Today the GRAI methodology uses four views, namely the functional, physical, decisional and informational systems, to provide the analyst with a generic description of the manufacturing system while focusing on the control aspects of this system. These views permit the building of partial models of the enterprise. Processes are seen from different viewpoints through the four views. For example, the role of the functional view is to create a simplified representation of the entire system showing the main functions (activities) within the system as well as the interactions between them. GIM uses IDEF0 diagrams to represent the functional view as well as the physical view. For the design of the informational system GIM uses MERISE that is based on Entity/relationships diagrams and Petri nets. Besides GRAI-GIM (Roboam, 1993) provides for its users: a modelling framework, a set of modelling formalisms, and 
a structured approach. The analysis of decisions within processes at GRAI GIM is based on GRAI grid and GRAI nets techniques to model processes with focus on the decisional flow. This is a unique feature of GIM. Thus, GRAI grid and GRAI nets permit building process models focusing on responsibilities and decision-making processes being more adequate to be used as a technique for the analysis and design of the process. GRAI grid and GRAI nets techniques were based on IDEF0 when invented.

\subsection{Simulation}

According to Kelton et al. (1996) simulation is a collection of methods and applications to imitate the behaviour of real systems. Simulation can be classified, according to certain characteristics, in deterministic (input data is fixed) or stochastic (input data is randomised), static (system descriptions in a mathematical way where time has no role) or dynamic (time plays an essential role) and continuous (systems change their state continuously) or discrete (events that occur at separated points of time). Processes seen as systems might be modelled using simulation for the purpose either of understanding the behaviour of the process or of evaluating various strategies for the operation of it either for decision-making or for learning purposes. However, simulation is based on other techniques such as Petri nets or OO methods when modelling systems, so the technique used will depend on the simulating device selected i.e. the tool. Today, there are many available simulation tools that can model all kind of systems, no matter its complexity. Nevertheless, from the user point of view the models can be created using the simulating device facilities without minding which technique is behind it. Likewise, the simulating device facilities give the user the possibility to simulate a process model made with one of the techniques presented in Section 3. This double interaction between simulation and the modelling techniques makes difficult the classification of simulation. However, the author of this paper considers it worth mentioning anyway since simulation represents a great possibility to model a business process. As a disadvantage simulation cannot model exactly the behaviour of a real system due to the huge number of variables involved. In general, simulation is not used when the system can be modelled analytically because it requires quite a big investment in time and resources.

\section{Proposal framework: Classification of process modelling techniques}

Practitioners and academics require simple and clear guidelines in order to facilitate the task of choosing the most appropriate technique. This section proposes a classification of the techniques according to their purposes and change model permissiveness. Earlier sections aid in understanding the positioning of each technique in this framework. As a result of the analysis carried out in these Sections 3 and 4, Table 1 was built to present a summary of the above techniques.

In order to make it easier and faster to view a relationship between each technique and some of its associated tools available in the marketplace, the table in the Appendix was developed. It is a summary list of the tools in alphabetic order. The table is based on information from Aguilar-Savén (2001) which in turn is based on the information presented by Kettinger et al. (1997a) and completed with information from vendors Web-based marketing material.

The techniques presented in Sections 3 and 4 can be classified according to the two dimensions described in Section 2, namely purpose of the model and model change permissiveness. Fig. 10 shows the resultant framework. The framework classification together with Table 1 is proposed to be used to choose among the business process modelling techniques. The idea is to provide users with a framework that helps them to decide which, among the explained techniques, is the one they should apply for a specific case.

Process modelling techniques might be used either to develop software that supports processes or to analyse the processes themselves. In both cases sometimes a model is required to describe the process either as a data capture or a presentation exercise. This aids learning about the process. Sometimes models are needed to make decisions on 
Table 1

Business process modelling techniques

\begin{tabular}{|c|c|c|c|c|c|c|c|}
\hline \multirow[t]{3}{*}{ Technique } & \multirow[t]{3}{*}{ Description } & \multirow[t]{3}{*}{ Attributes } & \multirow[t]{3}{*}{ Characteristics } & \multicolumn{4}{|c|}{ Strengths and Weakness } \\
\hline & & & & \multicolumn{2}{|l|}{ User perspective } & \multicolumn{2}{|l|}{ Modeller perspective } \\
\hline & & & & Strength & Weakness & Strength & Weakness \\
\hline $\begin{array}{l}\text { Flow } \\
\text { Chart }\end{array}$ & $\begin{array}{l}\text { Graphic } \\
\text { representation }\end{array}$ & Flow of actions & $\begin{array}{l}\text { Not sub-layers } \\
\text { Great details } \\
\text { No overview }\end{array}$ & $\begin{array}{l}\text { Communication } \\
\text { ability }\end{array}$ & Can be too large & $\begin{array}{l}\text { Flexibility quick, } \\
\text { simple }\end{array}$ & $\begin{array}{l}\text { No method } \\
\text { available } \\
\text { Different } \\
\text { notations }\end{array}$ \\
\hline DFD & $\begin{array}{l}\text { Descriptive } \\
\text { diagrams for } \\
\text { structured analysis }\end{array}$ & Flow of data & $\begin{array}{l}\text { Explains } \\
\text { logical level } \\
\text { sub-layers }\end{array}$ & $\begin{array}{l}\text { Easy to } \\
\text { understand }\end{array}$ & $\begin{array}{l}\text { Only flow of } \\
\text { data is shown }\end{array}$ & $\begin{array}{l}\text { Easy to verify } \\
\text { and draw }\end{array}$ & \\
\hline RAD & $\begin{array}{l}\text { Graphic view } \\
\text { object state } \\
\text { transition } \\
\text { diagrams }\end{array}$ & $\begin{array}{l}\text { Flow of individual } \\
\text { roles }\end{array}$ & $\begin{array}{l}\text { Detailed view } \\
\text { Degree of } \\
\text { empowerment } \\
\text { No overview }\end{array}$ & $\begin{array}{l}\text { Supports } \\
\text { communication } \\
\text { Intuitive to read }\end{array}$ & $\begin{array}{l}\text { Not possible to } \\
\text { be decomposed }\end{array}$ & $\begin{array}{l}\text { Include business } \\
\text { objects }\end{array}$ & $\begin{array}{l}\text { Different } \\
\text { notations }\end{array}$ \\
\hline RID & $\begin{array}{l}\text { Matrix } \\
\text { representation of } \\
\text { processes for } \\
\text { co-ordination of } \\
\text { activities }\end{array}$ & $\begin{array}{l}\text { Flows of activities } \\
\text { and roles }\end{array}$ & $\begin{array}{l}\text { Inputs to and } \\
\text { outputs from } \\
\text { are not } \\
\text { modelled } \\
\text { Performers are } \\
\text { included }\end{array}$ & $\begin{array}{l}\text { Intuitive to } \\
\text { understand }\end{array}$ & $\begin{array}{l}\text { Important } \\
\text { information is } \\
\text { not included }\end{array}$ & $\begin{array}{l}\text { Rigid notation } \\
\text { Complex processes } \\
\text { can be displayed }\end{array}$ & $\begin{array}{l}\text { Difficult to edit an } \\
\text { existing diagram } \\
\text { Hard to construct }\end{array}$ \\
\hline $\begin{array}{l}\text { Gantt } \\
\text { Chart }\end{array}$ & $\begin{array}{l}\text { Matrix } \\
\text { representation }\end{array}$ & $\begin{array}{l}\text { Flow of activities } \\
\text { and duration }\end{array}$ & $\begin{array}{l}\text { Relate } \\
\text { activities } \\
\text { to time }\end{array}$ & $\begin{array}{l}\text { Easy overview } \\
\text { representation } \\
\text { and control of } \\
\text { performance }\end{array}$ & $\begin{array}{l}\text { Not aid for } \\
\text { analysis or } \\
\text { design }\end{array}$ & Simple & $\begin{array}{l}\text { No clear } \\
\text { representation of } \\
\text { dependencies }\end{array}$ \\
\hline IDEF0 & $\begin{array}{l}\text { Structural } \\
\text { graphical } \\
\text { representation, } \\
\text { text and glossary }\end{array}$ & $\begin{array}{l}\text { Flows of activities, } \\
\text { inputs, outputs, } \\
\text { control and } \\
\text { mechanisms }\end{array}$ & $\begin{array}{l}\text { Based on } \\
\text { SADT } \\
\text { Sub-layers } \\
\text { The most } \\
\text { popular }\end{array}$ & $\begin{array}{l}\text { Shows inputs, } \\
\text { outputs, control } \\
\text { and mechanisms } \\
\text { overview and } \\
\text { details }\end{array}$ & $\begin{array}{l}\text { Trend to be } \\
\text { interpreted only } \\
\text { as a sequence of } \\
\text { activities } \\
\text { Roles are not } \\
\text { represented }\end{array}$ & $\begin{array}{l}\text { Strict rules } \\
\text { Possible to build } \\
\text { a software } \\
\text { Quick mapping }\end{array}$ & \\
\hline IDEF3 & $\begin{array}{l}\text { Behavioural } \\
\text { aspects of a system }\end{array}$ & $\begin{array}{l}\text { Precedence and } \\
\text { causality } \\
\text { relationships } \\
\text { between activities }\end{array}$ & $\begin{array}{l}\text { Allows } \\
\text { different views } \\
\text { Process flow } \\
\text { descriptions } \\
\text { and object state } \\
\text { transition } \\
\text { description } \\
\text { diagrams } \\
\text { Sub-layers }\end{array}$ & $\begin{array}{l}\text { Easy to } \\
\text { understand } \\
\text { dynamic aspects } \\
\text { in a static way }\end{array}$ & $\begin{array}{l}\text { Many partial } \\
\text { diagrams to } \\
\text { describe a } \\
\text { process }\end{array}$ & $\begin{array}{l}\text { Strict rules and } \\
\text { notation Possible to } \\
\text { build a software }\end{array}$ & $\begin{array}{l}\text { Need lot of data } \\
\text { Time consuming } \\
\text { when modelling } \\
\text { complex systems }\end{array}$ \\
\hline
\end{tabular}


Coloured Graphical oriented Petri Nets design, specify,
simulate and verify systems

Object Describe a system

Oriented with different type

Methods of objects

\begin{tabular}{|c|c|}
\hline Workflow & $\begin{array}{l}\text { Computerised } \\
\text { facilitation or } \\
\text { automation of a } \\
\text { business process }\end{array}$ \\
\hline $\begin{array}{l}\text { Rich } \\
\text { Pictures }\end{array}$ & $\begin{array}{l}\text { Contextual } \\
\text { representation } \\
\text { of things }\end{array}$ \\
\hline $\begin{array}{l}\text { GRAI } \\
\text { grid and } \\
\text { GRAI } \\
\text { nets }\end{array}$ & $\begin{array}{l}\text { Descriptive } \\
\text { diagrams of the } \\
\text { process focused } \\
\text { on decisions }\end{array}$ \\
\hline
\end{tabular}

Network of places, Extended Petri nets transitions and arcs

Object's structure

and behaviour

\section{Flow of}

information, tasks

and procedural

rules

Represent process

human

problematic

\section{Decision making \\ process and flow \\ of activities}

Token are

differentiated

by colours

Hierarchical

decomposition

Easy to
understand how
individual
processes
interact with
each other

Three concepts:

objects, classes

and messages

There are many

modelling

techniques

based on $\mathrm{OO}$

Flow of tasks

between

computers and

people

Decentralised

Represent

some of the

richness of the

process being

examined

Sub-layers

Distinction

between period and

event driven activities

Enactable model

to control and

monitor

processes

Easy to analyse

Shorter learning

time

\section{Support}

communication

and

understanding of

the process

outputs, control

and mechanisms,

overview and
Models are

excessively large

Model are excessively large and detailed

Fragmented

information

Shows inputs, details
Forma

mathematical

representation

Well defined

syntax and

semantics

Possible to build

a software

Data concepts

Internal

Time consuming

when modelling

when modelling

Complexity

and programming

Possible to build

a software
Possible build

a software

Data transfer

Easy to make

changes

Easy to illustrate

components as

clients, people,

tasks and

environment

Strict rules

and notation

Possible

to build a software

Lack of a

particular

notation

Many languages

Lack of a

particular notation

Need lot of data

Time consuming

when modelling

describe a

process

Complexity 


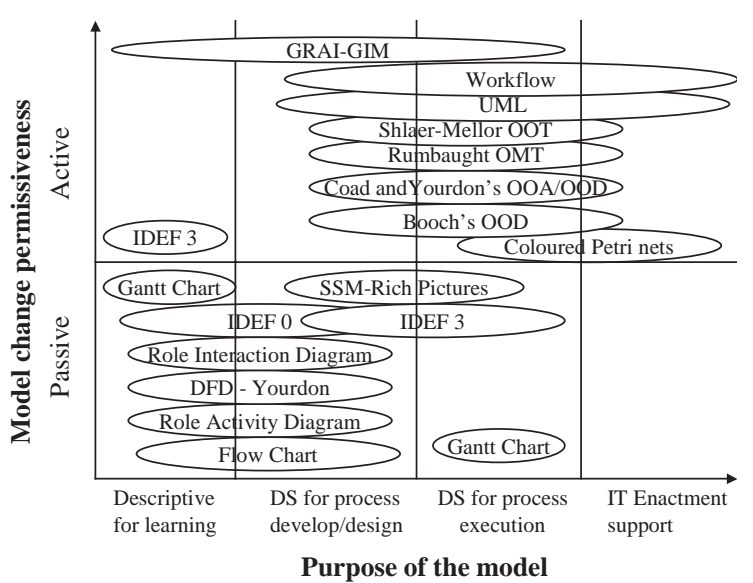

Fig. 10. Classification framework to select among business process modelling techniques.

the design, or on the development (changes, improvements or re-design) of processes. The aim in this case is to develop adequate business processes, so the purpose of these models is for analysis. Sometimes however when executing a process some decisions might be required to ensure its correct performance. Hence the need for some process models to control and monitor processes as well as to give right information in order to support those decisions. Interactive models are often of great use here. Finally, for the software development process, which supports business processes, enactable models are essential for programming. Therefore, uses or purposes of business process models might be divided into four main categories as follows:

(1) descriptive models for learning;

(2) descriptive and analytical models for decision support to process development and design;

(3) enactable or analytical models for decision support during process execution, and control; and

(4) enactment support models to Information Technology.

They will constitute the horizontal axis of our framework (see Fig. 10).

Another specific model characteristic is considered important for the present proposal framework always looking to make the framework as general and simple as possible: change model permissiveness. This characteristic pays attention to the level to allow and facilitate model changes. Analysis of the techniques identified has indicated that some of the models developed may be classified as passive. That is, they do not have the capability to allow the user to interact with, or change them without totally remodelling the process. In contrast, other models allow users to make changes, or are dynamic themselves. Examples include simulation and enactable models. Such models may be classified as active. Hence, the distinction between active and passive models is what we call change model permissiveness, and constitutes the vertical axis of our framework (see Fig. 10).

\section{Conclusion and further research}

Business process modelling is a much-researched field but is neither well structured nor classified. There exists considerable confusion on terminology. For example, OO has different interpretations and definitions. Some consider OO as a general methodology for process modelling. Others however may consider it a philosophy that shows how the "real world" behaves or may consider it to be just a simple technique. The same applies to SSADM, Workflow and GRAI. Hence there is a need to clarify, classify, organise and structure this field of research. The review and resultant framework presented in this paper is an attempt to fill this gap.

A classification framework to aid selection of process modelling techniques based on the purpose and type of model has been proposed. However, further research is required in order to classify the techniques according to other criteria such as experience, difficulties in use and suitability. Comparisons among the techniques would be of great help too.

There is still lack of a general framework on what a business process modelling technique must include to be successful. Some efforts carried out in this sense have given partial results so far. However, when integrating an enterprise, business process modelling techniques and 
tools cannot in themselves provide 'the solution'. They are an aid to business analysts to design and manage the processes, whose understanding is an essential function of communication and consensus in an enterprise. Hence, the capability of a tool to support communication and enhance understanding is of the highest importance.

Further research is required to analyse in detail the available process modelling tools in order to give users a complete description of the purpose, scope and use of each tool. This will also provide a comparative assessment and aid in their selection.

\section{Appendix}

Business process modelling techniques and their associated tools is given in Table 2. The purpose of this table is limited to inform readers about available tools. It is not intended to be a guide for users to select the appropriate tool. In this sense further research is needed.

Table 2

\begin{tabular}{|c|c|}
\hline Technique & Tools/Trademarks \\
\hline Flowchart & $\begin{array}{l}\text { ABC Flow Charter 4.0, ABC Graphics Suite, ABT Project Workbench, AWD and Workflow Analyzer, Bench } \\
\text { Marker Plus, BPM, Business Object Modelling Workbench, Cap Web-Flow, CLEAR, COI-Business Flow, } \\
\text { CORE, COSA, CSEWorkflow 5.0, Docu Flow, EPM SuiteFlow Maker, Flow Path, Flow PATH IMAGEWorks, } \\
\text { Flowcharter, Flowmark, Form Flow, Free Flow, GOOFEE Diagrammer, IBMBusiness Process Modeler, Ithink } \\
\text { (HPS), Jet Form Server, MAXIM, Net Prophet, OCTOFlow, Optix Workflow, PAVONE Group Flow, } \\
\text { PFTamptrade, Power Flow, Power Flow Team Flow Process Wise, Pro Model, Process Charter, Process Maker, } \\
\text { RKB Work Frame, SA/BPR Professional, Smart Flow 98, Vectus, Visual Thought, Work Flow Analyzer, Work } \\
\text { FLOW SQL, Work Flow.2000, Work Flow.2020, Work Xpert, Workflow FONT, CESymbolmiddot } \\
\text { FONTBPR, Workflow Modeler, Workflow.BPR, Trampolin. }\end{array}$ \\
\hline DFD- & ARIS-Tools, CASE Tool, 4Keeps, BONAPART, GRADE, INCOME, IEW, Paradigm Plus, Popkins Systems \\
\hline Yourdon & Architect, Softwarethrough Pictures SE, ProcessWise, With Class 98, Graphics Toll \\
\hline $\begin{array}{l}\text { Role activity } \\
\text { diagrams RAD }\end{array}$ & RADitor (Co-ordination Systems Ltd.) \\
\hline $\begin{array}{l}\text { Role interaction } \\
\text { diagram RID }\end{array}$ & RADitor (Co-ordination Systems Ltd.) \\
\hline Gantt chart & ABT Proyect Workbench, PFTamptrade, Project Scheduler7, Team Flow, Workflow BPR \\
\hline IDEF & $\begin{array}{l}\text { 4Keeps, AI0WIN, BPWin, Business Object Modelling, orkbench, CORE, Design IDEF, Design Leverage, IDEF } \\
\text { Tools, Popkins Systems Architect, Pro CAP Pro SIM, Process Maker, SA/BPR Professional and Workflow } \\
\text { Modeler. }\end{array}$ \\
\hline Petri-net-CPN & Desigh CPN, UNCOME, PACE, Process Maker and Process Weaver \\
\hline Booch OC & $\begin{array}{l}\text { 4Keeps, lass Designer, Paradigm Plus, } \\
\text { Softwarethrough Pictures Booch, With Class } 98\end{array}$ \\
\hline $\begin{array}{l}\text { Coad/Yourdon } \\
\text { OOA/OOD }\end{array}$ & 4Keeps, Paradigm Plus, Together C, With Class 98 \\
\hline $\begin{array}{l}\text { Rumbaught } \\
\text { OMT }\end{array}$ & 4Keeps, Paradigm Plus, Select Enterprise \\
\hline $\begin{array}{l}\text { Shlaer-Mellor } \\
\text { OOM }\end{array}$ & 4Keeps, Bridge Point Automation Tools, Paradigm Plus, SES/objectbench, With Class 98 \\
\hline UML OOM & $\begin{array}{l}\text { 4Keeps, Class Designer, COOLJex, Innovator, j-vision, Javision, LOREx2 for Java, Magic Draw UML, Object } \\
\text { Plant, Objecteering, Paradigm Plus, Pragmatica, Real-time Studio, Rhapsody, SDT, Soft Modeler Business, } \\
\text { Softwarethrough Pictures UML, Together C, Together J, Visual UML, With Class } 98\end{array}$ \\
\hline Workflow & $\begin{array}{l}\text { View Workflow, ABSI-Docss, Action Request System, Action Workflow Analyst, Action Workflow Application } \\
\text { Builder, Action Workflow Enterprise Series, Action Workflow Workflow Manager, ARIS, TIWorkflow } \\
\text { Distributor AWD, AWD and Workflow Analyzer, Beyond Mail, BONAPART, Business Object Modelling } \\
\text { Workbench, Cap Web-Flow, CMSWorkflow, COI-Business Flow, Computron Workflow, COOL, COSA, }\end{array}$ \\
\hline
\end{tabular}


Table 2 (continued)

\begin{tabular}{|c|c|}
\hline Technique & Tools/Trademarks \\
\hline $\begin{array}{l}\text { SSADM } \\
\text { Soft System } \\
\text { Methodology } \\
\text { GRAI GIM } \\
\text { Simulation }\end{array}$ & $\begin{array}{l}\text { CSEWorkflow 5.0, Designer2000, Docu Flow Document Manager, Documentrix Workmanager, EDI36, EDI38, } \\
\text { EDI400, EDIe Qmail, Engineering Workflow System, Ensemble, Enterprise Analyst, Entire Workflow, EPM } \\
\text { Suite, Extend BPR, Fabasoft Components, File Net Work Flow, Flo Ware, Flow Maker, Flow Man, Flow PATH } \\
\text { IMAGEWorks, FLOWBuilder, Flowmark, Form Flow, FORO, FYI, FYI Workflow, Group Wise, IBIsys, } \\
\text { IBMBusiness Process Modeler, IBS Workflow Manager, Image Fast, Image Master, In Concert, Inter Office, Jet } \\
\text { Form Server, Key Workgroup, Keyflow, Lifeflow, Life FLOW, Link Works Team Links, Linkworks, Livelink } \\
\text { Intranet, MAVIM 3, Memo, Message Driven processor MDp, Metaphase 2.0, Metaview FOLDERS, METEOR, } \\
\text { Metis, Navigator 2000Document Management Systems Navigato, Navigator 2000Workflowm, Nova Manage, } \\
\text { OCTOFlow, ODMS, Office.IQ, Open Image, OPENworkflow, Optix Workflow, PANOVE Group Flow, Plexus } \\
\text { Flo Ware, Power Flow, Power Flow Team Flow Process Wise, Power Work, Process IT, Protos, Radica, Regata, } \\
\text { Route Builder Omni Desk, SAP Business Workflow, Smart Flow 98, Smart Stream, SPARKS G2, Struct Ware, } \\
\text { The Vantive System, Ultimus, Viewstar Workbench, Win Work, Wizdom Works, Work Fast, Work Flow } \\
\text { Analyzer, Work MAN, Work Party, Work Xpert, Workflow FONT FACESymbolmiddot, FONTBPR, } \\
\text { Workflow.BPR, WORKlogik TM, World Wide Web Flow W4, Xworkflow } \\
\text { 4Keeps, SSADM } \\
\text { Group Decision Support System (GDSS), Group system (Ventura Corp) } \\
\text { IMAGIM, CAGIM (Computer Aided GIM), DGRAI } \\
\text { AWD and Wordflow Analyzer, BONAPART, BPSimulator Template, Business Object Modelling Workbench, } \\
\text { Business Process Analyzer Bwise Toolkit, CABRE-Witness Cinderella SDL, CLEAR, Clear Process, Design } \\
\text { CPN, Design Leverage Dress Rehearsal, EPM Suite, First STEP, Flowcharter GRADE HITSoft BIZ, HOCUS, i- } \\
\text { think Ithink, Live Analyst, METIS, Micro SAINT Object GEODE, Optima, Optima Express, Oracle Process } \\
\text { Manager, PACE, PAVONE Group Flow, Powersim, ProModel, ProModel2.0, Process Charter Prophesy, } \\
\text { PROSIM Process Modeling Software, Quick CRC, RDD-100, SES/Workbench, SIMAN amp ARENA, } \\
\text { SIMPROCESS, Soft Modeler Business, SPARKS G2, Statemate Magnum, Struct Ware, Surveywin Taylor II, TI } \\
\text { BDF, Vectus, Vensim, Witness, Workflow Analyzer, Workflow FONT FACESymbolmiddotFONTBPR, } \\
\text { Workflow BPR }\end{array}$ \\
\hline
\end{tabular}

\section{References}

Adams, J.D., 1984. Transforming Work. Miles River Press, Alexandria, VA, USA.

Aguilar-Savén, R., 2001. Business process modelling techniques and tools. Department of Production Economics. WP291, Linköping Sweden.

Aguilar-Savén, R., Olhager, J., 2002. Integration of product, process and functional orientations: Principles and a case study. Preprints of the International Conference on Advanced Production Management System, APMS 2002, IFIP, September, The Netherlands.

Al-Mubarak, F., 2003. A simulation study of focused cellular manufacturing as an alternative batch-processing layout. International Journal of Production Economics 83 (2), $123-138$.

Artiba, A., 2001. Productive systems: Strategy, control, and management. International Journal of Production Economics 74 (1-3), 1-4.

Barros, A.P., Hofstede, A., 1998. Towards the construction of workflow suitable conceptual modelling techniques. Information Systems Journal 8 (4), 313-337.
Booch, G., Rumbaugh, J., Jacobson, I., 1999. The Unified Modelling Language User Guide. Addison-Wesley, USA.

Boma, 1996. Process definition, available at http://www.sesh. com/procdef.html.

Bruce, P.D., 1998. Real-Time UML, Developing Efficient Objects for Embedded Systems. Addison-Wesley, USA.

Chan, M., 2002. A framework to develop an enterprise information portal for contract manufacturing. International Journal of Production Economics 75 (1-2), 113-126.

Coad, P., Yourdon, E., 1991. Object-Oriented Analysis, 2nd ed. Prentice-Hall, Englewood Cliffs, NJ, USA.

Coad, P., North, D., Mayfield, M., 1995. Object Models: Strategies, Patterns and Applications. Prentice-Hall, Englewood Cliffs, NJ, USA.

Davenport, T.H., 1993. Process Innovation: Reengineering Work through Information Technology. Harvard Business School Press, Boston, MA, USA.

Doumeingts, G., et al., 1996. State of the art on models, architectures and methodologies. In: Bernus, P., Nemes, L., Williams, T.J. (Eds.), Architectures of Enterprise Integration. IFIP/Chapman \& Hall, London, pp. 223-255. 
Downs, E., Clare, P., Coe, I., 1992. Structured Systems Analysis and Design Method, 2nd ed. Prentice-Hall, Englewood Cliffs, NJ, USA.

ENV 12 204, 1995. Advanced Manufacturing TechnologySystems Architecture - constructs for Enterprise Modelling. CEN/CENELEC.

Fischer, L.J., 1995. New Tools for new Times: The Workflow Paradigm. Future Strategies. ISBN 0-9640233-2-6.

Falkenberg, E.D., et al., 1996. A framework of Information System Concepts. IFIP WG 8.1 Task group FRISCO. Leiden University, Leiden.

Giaglis, G., Doukidis, G., 1997. Simulation for intra- and interorganizational business process modelling. Informatica (Ljublana) 21 (4), 613-620.

Goldkuhl, G., Röstlinger, A., 1988. Förändringsanalysis. Linköpings University, Studentlitteratur, Sweden.

Guinet, A., 2001. A design and application methodology for hierarchical production planning decision support systems in an enterprise integration context. International Journal of Production Economics 74 (1-3), 5-20.

Hammer, M., 1990. Reengineering work: Don't automate. Obliterate. Harvard Business Review 68 (4), 104-112.

Hammer, M., Champy, J., 1993. Reengineering the Corporation: A Manifesto for Business Revolution. New York, USA.

Harmsen, A.F., 1997. Situational Method Engineering, Ph.D. thesis. Moret, Ernst \& Young Management Consultants, Utrecht, Holland.

Harrington, J., 1991. Business Process Improvement: The Breakthrough Strategy for Total Quality, Productivity and Competitiveness. McGraw Hill, New York, USA.

Hollingsworth, D., 1995. The Workflow Reference Model. Workflow Management Coalition, UK. Available at http:// www.wfmc.org.

Holt, A., et al., 1983. Coordination systems technology as a programming environment. Electrical Communication 57 (4), 307-314.

Hommes, B., et al., 2000. Assessing the quality of business process modelling techniques. Proceedings Hawaii International Conference on Systems SCI, IEEE. Los Alamitos, CA, USA, p. 5.

http://panoramix.univ-paris1.fr/CRINFO/dmrg/MME/misop025/ info.html.

http://threesl.com/data_flow_diagrams.htm.

http://www.daimi.au.uk/PetriNets/tools/quick.html.

http://www.slac.standford.edu/ marino/html/booch/method. html.

http://cheetah.sdd.sri.com/eliot/ads/shlaer-mellor.html.

IDEF (2003). Family of Methods web page: http://www. idef.com.

Jarzabek, S., et al., 1995. Model-based support for business reengineering. Information and Software Technology 38 (5), 355-374.

Kelton, W., Sadowski, R., Sadowski, D., 1996. Simulation with Arena. McGraw Hill, New York, USA.

Kettinger, W.J., Teng, J., Guha, S., 1997a. Business process change: A study of methodologies, techniques and tools.
Journal of Management Information Systems 14 (1), 119-154.

Kettinger, W.J., Teng, J., Guha, S., 1997b. Appendices business process change: A study of methodologies, techniques and tools. Management Information Systems Quartely Archivist 14 (1), Appendices 1-8.

Lakin, R., et al., 1996. BPR enabling software for the financial services industry. Management services, ISSN: 0307-6768.

Levitt, J., 1960. Marketing myopia. Harvard Business Review (July/August), pp. 45-56.

Macintosh, A.L., 1993. The need for enriched knowledge representation for enterprise. Artificial Intelligence in Enterprise Modelling, IEE Colloquium on, pp. 3/1-3/3.

Nicholas, D., 2003. Introducing SSADM available in http:// www.bdris.com/SSADM1.html.

Martínez, M.T., et al., 2001. Virtual enterprise-organisation, evolution and control. International Journal of Production Economics 74 (1-3), 225-238.

Oakland, J.S., 1993. Total Quality Management: The Route to Improving Performance, 2nd ed. Nichols Publishing, New Jersey, USA.

Pandya, K., 1995. Review of modelling techniques and tools for decision making in manufacturing management. IEE Proceedings: Science, Measurement and Technology 142 (5), 371-377.

Phalp, K.T., 1998. CAP framework for business process modelling. Information and Software Technology 40 (13), 731-744.

Phalp, K., et al., 1999. Quantitative analysis of static models of processes. Journal of Systems and Software 52 (2), 105-112.

PROCESS, 2003. Modelling and mapping the business process, EPSRC project, home page at: http://www.ecs.soton.ac.uk/ $\sim \mathrm{kp} /$ process.html.

Rajala, M., et al., 1996. A framework for customer oriented business process modelling. Computer Integrated Manufacturing Systems 9 (3), 127-135.

Roboam, M., 1993. La Methode GRAI. Principes, Outils, Démarche et Pratique. Teknea, Toulouse, France.

Rumbaugh, J., Blaha, M., Premerlani, W., Eddy, F., Lorensen, W., 1991. Object-Oriented Modelling and Design. PrenticeHall, Englewood Cliffs, NJ, USA.

Soft Systems Methodology web page: http://members.tripod. com/SSM_Delphi/ssm4.html.

Swanson, L., 2003. An information-processing model of maintenance management. International Journal of Production Economics 83 (1), 45-64.

Toussaint, P.J., Bakker, A., Groenewegen, L., 1997. Constructing an enterprise viewpoint: Evaluation of four business modelling techniques. Computing Methods and Programs in Biomedicine 55 (1), 11-30.

UML, 2003. Resource Center web page: http://www.rational. $\mathrm{com} / \mathrm{uml} /$ index.jsp.

Workman, J.C., et al., 2000. On the relation between business, business model, software, and ACT-platform architectures. Information and Technology Division. Eindhoven University of Technology, The Netherlands. 